\title{
Assessing experiential learning - us, them and the others
}

\section{Richard Grimes ${ }^{1}$ and Jenny Gibbons ${ }^{2}$}

\section{University of York, UK}

\section{INTRODUCTION}

This paper looks at the assessment of experiential learning primarily in the context of the learning and teaching of students using 'hands-on', interactive and reflective methods. It will, at various points, also refer to the evaluation of programmes and modules in terms of their impact and where improvements, in pedagogic terms, can be made.

The 'us' here are the teachers/tutors who are employed to promote, support and otherwise facilitate the advancement of the students'/learners' education. The 'them' is the student body on a particular course of study. The 'others' are those who have a vested interest in the form, content and means of measuring achievement of and in legal education - be they professional regulatory bodies, employers or the wider public.

The term 'experiential learning' refers in this setting to an approach to education in which students are exposed to real or realistic legal issues and problems. In this

\footnotetext{
${ }^{1}$ Richard Grimes is Director of Clinical Programmes at the York Law School, University of York UK. He is a solicitor and was formerly a partner in a provincial law firm in the north of England, Director of the Institute of Justice and Applied Legal Studies at the University of the South Pacific, Professor and Head of Law at the University of Derby and Professor and Director of Pro Bono Services at The (then) College of Law of England and Wales 2 Jenny Gibbons is a supervising solicitor in the Law Clinic at the York Law School. She is also a programme leader and module leader on the LLB at the York Law School and formerly taught on academic and vocational law programmes at BPP Law School.
} 
process they are required, in a structured way, that may or may not lead to the award of academic credit, to apply theory to practice and then deconstruct and analyse what took place (or did not as the case may be) and why. In the world of legal education an experiential approach to study is often termed 'clinical' and the word 'clinic' will appear frequently throughout this paper in referring to the vehicle through which experiential learning may be presented and delivered.

Finally, by way of introduction, the word 'assessment' is intended to include the measurement of both the quality and extent of student learning (regardless of whether academic credit is gained) and the perceived value of what is being delivered from a learning and teaching perspective, by the 'us', the 'them' and the 'others'.

\section{A STARTING POINT}

Unless one is talking about 'right' and 'wrong' answers as determined by the assessor and measured by pre-defined criteria, for example in a multiple choice test, we maintain that there is little or no precise science in assessment. Rather there are processes and systems aimed at establishing what has been termed elsewhere as validity, reliability and impact. ${ }^{3}$ We also suggest that assessment in an experiential

\footnotetext{
${ }^{3}$ See Cees PM Van Der Vleuten and Lambert WT Schuwirth, Assessing professional competence: from methods to programmes, Medical Education 39, 309-317, 2005. The same authors make the important point that there are no inherently good or bad means of assessment. We suggest whilst this is an important observation there are certainly better and worse ways and will explore this in the context of clinical legal education shortly.
} 
or clinical setting is no different, other than the nature of such study perhaps more readily lends itself to innovative methods of assessing. This will be explored more fully later.

If there are no definitives or absolutes on how we assess, we must seek the means by which to establish and ensure the applicability, value and credibility of the relevant process if we wish to justify and monitor what is taking place. In our experience this inevitably means devising a set of guidelines and safeguards starting with an explicit iteration of what is expected, in terms of student performance (typically what the student is intended to achieve). This begins, at least in educational parlance, with what are commonly termed 'learning outcomes'. We suggest that it is not possible to assess any aspect of a module, course or programme, either student performance or the effectiveness of the teaching and learning, unless clear learning outcomes are set in advance of the period of study and that these are made apparent to and/or by both student and tutor at the outset. The importance of the learning outcome as a pre-requisite to effective assessment is well documented elsewhere and we wish to simply underline its significance here. ${ }^{4}$

The second of our essentials in terms of a starting point can be summarised by the often quoted acronym SMART. ${ }^{5}$ Although this has had term has assumed various

${ }^{4}$ See: Clauis Nygaard, Clive Holtham and Nigel Courtney, Improving students' learning outcomes, Copenhagen press, 2009. For a wealth of resource materials and instructive discussions see: www.learningoutcomesassessment.org and in particular the transparency framework, accessed 15 October 2015

${ }^{5}$ For a useful and very well-referenced discussion about SMART principles in general and the link with learning outcomes in particular see: K. Blaine Lawlor and Martin J. Hornyak, Smart goals: how the 
incarnations it is normally taken to stand for Specific, Measurable, Appropriate, Relevant and Timely (or time-bound).

We maintain that both module/programme outcomes and assessment tasks should be SMART. What does this mean in practice? A range of pertinent questions arise:

- Having set clear learning outcomes, do the means used for assessing whether they have been achieved relate specifically to each of the relevant outcomes?

- Are the outcomes and is the assessment regime fitting in terms of the level of the student's study, the juncture at which the outcome is expected to be achieved and when the assessment is to be carried out?

- Are the outcomes and means of assessment likely to be perceived by the tutor and student as applicable to the relevant study?

- Can the outcomes and assessment be logistically fitted into the period of study and any assessment slot that may follow it?

- Does the whole have credibility for tutor and learner? In other words is there 'buy-in' or ownership by all concerned?'

The third point concerns feedback - an essential component and potential complication in any form of learning and teaching. This too can be dealt with, in part, under the SMART umbrella. Whether or not the students receive marks or grades we suggest that feedback is, unless we are concerned only with the immediate demonstration of competency (such as a driving test), a vital component application of smart goals can contribute to achievement of student learning outcomes, Developments in Business Simulation and Experiential Learning, volume 39, 259, 2012 
of the learning process. ${ }^{7}$ It is sometimes suggested, implicitly at times, that feedback itself is formative assessment whereas the allocation of a number or letter is summative. ${ }^{8}$ We dispute this. Feedback without a mark or grade, be it oral, written and provided by self, tutors and/or peers may be taken to mean 'formative' assessment. Typically end of module/course/programme assessment, where students receive their results, coupled possibly with inter-year ranking, is termed 'summative'. In our view however there is no reason why assessment cannot serve both purposes at the same time and indeed, unless we are solely measuring competence at a defined moment in time, there is every reason why it should. ${ }^{9}$ The 'us' and the 'them' are likely to find the formative/summative assessment hybrid has most value when used for the dual purpose of measuring performance and enhancing learning whereas the 'others', notably regulators and perhaps the wider public interested in the quality of what is emanating from our universities and colleges, may be more interested in a demonstration of competency at the point of exit from or entry to the various stages of the professional education progression Medical education, 47(7), 734-744.

8 For a discussion of the relationship between formative and summative assessment see: Kay Burke, Balanced assessment: from formative to summative, Solution Tree Press, 2010 and M.Taras, Summative assessment: the missing link for formative assessment, Journal of Further and Higher education, Vol. 33, 2009, 1

9 See also: Van der Vleuten, C. P. M., Schuwirth, L. W. T., Driessen, E. W., Dijkstra, J., Tigelaar, D., Baartman, L. K. J., \& van Tartwijk, J. (2012). A model for programmatic assessment fit for purpose. Medical Teacher, 34(3), 205-214. 
map. Passing a bar examination as required in many countries, (notably US states) and possibly to become the norm in the UK, is an example of such. ${ }^{10}$

The importance and value of assessment from both formative and summative perspectives is stressed by a number of writers and the desirability of a balance (or at least extensive use of both to enhance learning) is powerfully made by Sambell et $a l .{ }^{11}$

Our final comment under these basic principles concerns the means by which assessment is carried out. For tutors and students this normally takes one or more of the following forms: written examinations (seen or unseen; open or closed book), course work (essays and other written tasks), oral presentations - including reports, role-play and the viva voce (although in our experience these are means that are largely under-used in legal education outside perhaps of clinical skills and overtly vocational courses), portfolios (ranging from collections of students' work to reflective submissions), entry and exit questionnaires and attendance/class contribution. One developing area of practice is the use of on-line tools for assessment, which we would suggest certainly have their place in a clinical context.

10 The most recent consultative document by the solicitors' regulator in the UK, the SRA, suggests that testing competency at the point of admission may well be required in future. (Training for Tomorrow: A Competence Statement for Solicitors, 2014 - we are awaiting the outcome of this consultative process). At the time of writing it is unclear if the barristers' regulator, the BSB, will require a similar provision. The BSB already has centralised examination components for the relevant vocational course (the Bar Professional Training Course or BPTC). For admission into legal practice in the UK there are currently a series of hurdles staring with undergraduate qualifications and progressing through a required vocational course and finishing with the completion of an apprenticeship although this, too, is under review.

${ }^{11}$ Kay Sambell, Liz McDowell and Catherine Montgomery, Assessment for learning in higher education, Routledge, 2013, 32-48 
A fuller picture of the means by which assessment can be carried out is usefully listed elsewhere. ${ }^{12}$

It is entirely justifiable in our view that, providing the means by which assessment is carried out are clearly articulated and aligned with learning outcomes, then any or all of the means listed or referred to above may have their place. Clearly some may be more appropriate than others, given context, and in a clinical setting, for example, it is unusual to have a written examination. That said each format for assessment may be appropriate and the combination used in any particular module or programme should surely be structured to both best assess the level of performance and to provide students with the opportunity of maximising their learning opportunities (and end result capacity)?

As indicated above the often intimate confines of experiential work, where students may be exposed to regular and frequent tutor contact and on-going feedback lends itself to particular assessment forms. This is explored below.

\section{THE COMPLICATIONS}

So far so good. The basics outlined above are, we think, clear and applicable across a range of learning situations, experiential and otherwise.

Let us now turn to learning in an experiential clinical setting. First, some definitions: 
As suggested already, by experiential we mean exposing students to learning and teaching situations where they are expected to apply theory to practice in some guise. This may be through role-play, through simulated case studies or, as we focus on below, in 'live-client' work. This exposure provides both an opportunity to experience the application of knowledge and (depending on outcomes set) related skills and values and to deconstruct and reflect upon the experience gained. ${ }^{13}$ We use the word 'clinic' or 'clinical' at various junctures in this paper. Here we mean the use of real or realistic situations where students engage in legal casework or address and analyse legal issues based on the exposure to such. This inevitably means that the learning is experiential but can be distinguished from the generic term in that clinic, in its various forms, involves both the experience and a structured facility for refection and (possibly) re-application. The clinical models in which this learning can take place are well documented elsewhere and range from simulation through legal advice and representation to campaigning work and legal literacy programmes. ${ }^{14}$

One final defining term relates to the importance of the compliance of all parties with professional standards within clinical legal education. By professional

\footnotetext{
${ }^{13}$ For a discussion of the role of learning and teaching through simulation see: Caroline Strevens, Richard Grimes and Edward Phillips Legal education: Simulation in theory and practice, Ashgate, 2014 and for the live-client dimension see: Hugh Brayne, Nigel Duncan and Richard Grimes, Clinical legal education: active learning in your law school, Blackstone Press, 1998 ${ }^{14}$ The models of clinic are set out and analysed in: Kevin Kerrigan and Victoria Murray (Eds), $A$ student guide to clinical legal education and pro bono, Palgrave Macmillan, 2011 and for a more international view see: Frank S Bloch, The Global Clinical Movement: educating lawyers for social justice, Oxford University Press, 2011
} 
standards we mean the knowledge of (and more importantly the practice and application of) concepts such as conflicts of interest, client confidentiality and professional values. It also includes procedural matters such as keeping client files in order and working with deadlines. For the 'us' this is for our own professional credibility and to satisfy the compliance requirements of the 'others'. For the students this is an important aspect of their learning in relation to professional standards and professional values, and it compliments other parts of the curriculum where these issues are taught often in the abstract.

The first complication comes with the reflective nature of experiential learning. Kolb's well-known (if much critiqued) learning cycle sums up the process well, even if it may not be as simple as the graphics Kolb uses suggest. ${ }^{15}$ If students are in a state of constant or at least regular application, abstraction and re-application and much of this involves using teaching staff and co-students as sounding boards, whose work in the end is being assessed? In some ways those who suggest that clinic is problematic because of the influence of tutors in the students' final products are perhaps being disingenuous as would they fail to respond to a student enquiry at the end of a lecture or seminar on the basis that it may skew what the student

${ }^{15}$ A new edition of Kolb's book - David Kolb, Experiential learning: experience as the source of learning and development, Peasrson Education, 2014 - has recently been published in which he helpfully addresses the criticisms levelled against the initial iteration that the original theory was rather onedimensional. 
eventually produces in the exam room or in an essay? ${ }^{16}$ Presumably not. The 'us' amongst readers surely intend to assist students and influence, in terms of the progression of their learning, their understanding, assessed or otherwise. On the other hand the extent of tutor input in most clinical settings is often extensive and therefore, understandably, open to suggestions of significant impact on the students - out of alignment with contact that those students (and importantly others without such exposure) may have in the rest of their studies.

This clearly raises a subjectivity issue, one that in fairness runs through the world of assessment and can only be answered satisfactorily when considering the individual assessment regime and any related moderation processes - see below.

The next challenge is associated with the teaching environment - one where the role of the student group is often to the fore. Where students work intensively with each other as a structured part of the programme how do the assessors determine who is responsible for what work that has been done? Also, should assessment reflect the group's input or that of the individual?

Of course the simple answer is to be found by asking and answering: what are the learning outcomes? If effective group work is one of them is the evidence of performance how well the group functions and, if so, therefore should all members share in the same level of relative success?

${ }^{16}$ Lest it be thought that our own, admitted, enthusiasm for experiential learning blinds us criticism see a powerful critique of the notion and practice of clinical legal education in Robert J Condlin, Tastes great, less filling: the law school clinic and political critique, Journal of Legal Education, 36 (1), 1986, 45 
The final difficulty here is the fact, in live-client clinical work at least, that students will inevitably have different clients with different problems. If we are assessing how they perform does the varying experience make a difference in terms of validity and reliability?

To bring some of these issues together let us take an example...

Imagine a law school clinic where students operate in groups (or as it is often termed 'firms'). Group 1 under this model has an interview with an emotionally upset client in a sensitive family law case. The interview lasts over an hour and litigation looks to be a likely course of future action. The client has never been to court before and she is very uncertain of the process and anxious about the consequences. The students work particularly hard to extract the case details and to reassure the client.

By contrast Group 2 have a client who is seeking advice on a small business set up. She is relatively experienced in matters commercial and brings to the interview a set of papers and questions she feels she needs assistance with. The interview is over in under half an hour and the students feel they were provided with most of the information they needed without detailed questioning of what turned out to be a very informed and at ease client.

The fictional (but we suggest, realistic) module that both sets of students are taking here is credit-bearing. What is the significance of their differing experiences? Of course the answer depends primarily on what learning outcomes have been set - is 
interviewing competence being 'tested'; is it the professionalism of the students in client-care up for examination; or, is the interview merely a vehicle for other outcomes such as applied legal research, subsequent drafting skills or a critique of the adequacy of the law in relation to client/societal needs? The module involved may, of course, have a combination of learning outcomes to be achieved covering a mix of legal knowledge, lawyering skills and/or professional values, personal attributes and broader ethical concerns.

In terms of purely formative assessment (in the sense of assessing their work with the sole purpose of enhancing learning - typically through oral or written feedback) the difference is probably very slight. Yes, the experience has been different but through probing a tutor could establish what happened, what could have happened (for example by asking 'what if your client had been less responsive or more confident?'), what might be done differently next time and what the wider implications are in terms of shaping policy and possible law reform?

When it comes to allocating marks or grades in a more traditional summative assessment model the situation could be very different especially if the nature and extent of the interviewing experience affects the opportunity for the student to meet the established assessment criteria. So how can these potentially significant challenges be addressed to ensure, so far as is possible, Van Der Vleuten's call for validity, reliability and impact? 


\section{A MODEL FOR EXPERIENTIAL ASSESSMENT}

We suggest, based on the literature (albeit primarily in a non-legal education context) and from personal experience in hands-on learning situations, that particular forms of assessment have a certain resonance in experiential learning in general and in 'clinic'. In particular we consider that these are the learning portfolio, tasks based on simulation, oral examinations (viva voce) and the on-line assessment of the appreciation of applicable professional standards.

Whatever form of assessment is used the charge of subjectivity raised above needs to be addressed. We suggest that this is done through a robust moderation process both in-house and externally. Let us now turn to these identified assessments' formats:

\section{The learning portfolio}

By 'learning portfolio' we mean a document produced by a student that catalogues the key elements of their learning experience and which includes reflective content. This latter point is what differentiates a learning portfolio in experiential learning from a portfolio produced in other subjects, most notably art; that is a collection of student generated work. The use of learning portfolios in clinical legal education is not a new idea, and there are an increasing number of resources available to help the 'us' to guide the 'them' in how to document and evidence their learning 
experience. ${ }^{17}$ We do not intend to replicate any of the 'how to' guidance here. Our focus here is on the 'why'.

From our day-to-day interactions with students in clinic it is clear that for the majority of them it is a transformative experience. In all stages of the process, from evaluating the basic case, to preparing for interview, identifying the clients' needs, researching the legal issues, drafting the letter - and beyond - the students readily articulate in conversation that they have learning from the experience. The learning portfolio as an assessment task is a way for the students to capture and express the extent of this learning and receive credit (either formal or not) for the way they articulate this developmental process.

There is scope for a learning portfolio to demonstrate whatever aspects of the experience is required by the learning outcomes and the assessment framework. We would suggest that the scope of the content can be very broad, for example it can include discussion on the types of cases undertaken, the substantive law, the procedural rules, the legal skills involved and the professional and ethical issues encountered. The reason the content can be so broad, is that the assessment is of the students' reflection on their experience, rather than the actual experience itself. The experience is therefore a vehicle for the reflection.

${ }^{17}$ For useful guidance on the use of reflective portfolios see the work of Moon, most notably, Jennifer Moon, Learning Journals: a handbook for reflective practice and professional development, Routledge, 2006 
How to facilitate reflective practice is another topic in itself and that will not be explored here. It is however widely accepted that reflection is an important component of experiential learning and comprehensive guidance can be found elsewhere. ${ }^{18}$ The discussion here is on why the reflective element of a learning portfolio is of such benefit to students in a clinical context, and for this we can link back to the example set out above.

In the Group 1 example, the firm has had a particularly rich, if demanding, experience in terms of the skill of interviewing, and in their need to understand and explain the substantive and procedural rules of family law. However, even within the firm possibly only two or three of the students will have conducted the interview and not all of the students might have undertaken the consequent research or drafting required. Where a learning portfolio is an assessment item this lack of equivalence is of limited concern as it is for the students to decide which aspects of their experience they focus upon within their critical analysis of that experience and the framework set by the outcomes expected and assessment tasks set.

The rationale for the use of learning portfolios is even stronger when you consider the Group 2 example. Although on the face of it their experience of clinic has been less intense and possibly 'poorer' as a result, there is still a wealth of material they can explore within the learning portfolio. For example, they could critique the relationship between a client and a lawyer, or reflect upon any shortcomings in the ${ }^{18}$ See for example, Anne Brockbank and Ian McGill, Facilitating reflective learning in Higher Education OUP 2007 
law in relation to setting up small businesses. The flexibility of the learning portfolio as an assessment item ensures that it is the quality of the reflection on the experience is of more importance than the experience itself. The students could also reflect on the 'what if', for example where a client may not have been so forthcoming. This all sounds great for 'them', but how about 'us' and the 'others'?

For 'us', we (as academics and legal practitioners in an institution driven by problem-based learning and where assessment is dominated by reflective submissions) initially found the marking of learning portfolios particularly problematic. How is it possible to mark fairly the submission from a Group 1 student and the submission from a Group 2 student when they are so different in content and where we are working with prescribed marking criteria? We have found our way through this by the adoption of a range of techniques. For example we give clear instructions about the task in a group plenary at the beginning of clinic where we make explicit the link between the assessment tasks and the learning outcomes. We also provide ongoing feedback in our conversations with students, and actively encourage them to create a personal reflective journal or diary during their time in clinic. Finally, and perhaps most importantly, we utilise a robust moderation process in an attempt to try and eliminate the inherently subjective nature of the assessment of reflective writing. Here two of 'us' independently mark submissions and an 
external examiner reviews a sample of work across the marking spectrum together with the feedback given to the students concerned. ${ }^{19}$

What is the view of the 'others' on learning portfolios and reflective writing? In other disciplines, most notably medicine and social work, such assessments are highly valued but this does not seem to play out in legal education. It is perhaps inevitable that regulators, the profession, other employers and the wider public are more concerned with demonstrations of competence rather than the production of an erudite 'academic' treatise. This is an area where we have a role in changing the perceptions of the 'others' by evidencing the impact of reflective practice in the students' ability to obtain the requisite competence. This is a work in progress. For those (apart from us) interested in developing thoughts around experiential learning and competency, Miller's work on measuring competency may be helpful in shaping assessment policy. ${ }^{20}$

\section{Tasks based on simulation}

As we have identified above, live-client clinics do not necessarily provide students with equivalence of experience. This can be problematic if you have learning outcomes that require students to, say, demonstrate legal knowledge. One useful

${ }^{19}$ Something similar has been proposed, using strategies from qualitative research. See: Driessen, E., Van Der Vleuten, C., Schuwirth, L., Van Tartwijk, J., \& Vermunt, J. D. H. M. (2005). The use of qualitative research criteria for portfolio assessment as an alternative to reliability evaluation: a case study. Medical Education, 39(2), 214-220.

${ }^{20}$ Miller GE. The assessment of clinical skills/competence/performance. Acad Med1990, 65 
way to assess students that is designed to mitigate against this problem is a task based on simulation.

Simulation is well used in experiential learning and, for many providers of clinical legal education, simulated clients are the only clients the students encounter. ${ }^{21}$ Our position is that there is space for tasks based on simulation even when working in a live-client environment. The use of simulation can help to minimise the three key complications referred to above and is, in any event, valuable preparation for handling real clients and the related casework at some later stage.

The first complication we have raised is the influence of tutors in the students' final products in clinic, which is most likely to be a letter of advice to a client. For the 'us ' amongst the readers, we know all too well that the level of personal input into advice letters varies widely between types of cases, and the ability or effort levels of student groups. The second complication links to the first and is based on the important place of group work within experiential learning. The third of our complications is lack of equivalence. If a clinic assessment was based on the 'real' letter of advice to the client it would be very difficult to evaluate the impact of the supervisor's involvement, or attribute marks in accordance with contribution. It would also be unfair on students who had been allocated particularly easy or difficult live-client cases.

\footnotetext{
21 The use of the 'standardised client' as a vehicle for simulated clinical work in a legal context is discussed at length in Adrian Evans, Assessing Lawyers' ethics: a practitioner's guide, Cambridge University Press, 2011 and in Paul Maharg, Transforming legal education: learning and teaching the law in the early Twenty First Century, Ashgate Publishing, 2007
} 
An assessment item based on a simulated client is a way around these complications. All of the students in a clinic cohort can be given the same client instructions, the same fact pattern, the same precedent documents and the same time limits. If the task is presented to students after they have completed their live-client cases it can be treated as the final case, and given the same level of focus and attention as the real clients. The students can then use their real life experience to inform them when they carry out the simulation-based assessment task. Simulation can, of course, stand alone as a means of teaching and learning as well as assessment. We suggest however that linking the real and the simulated provides rich material for learning and helpful assessment opportunities. ${ }^{22}$

The 'others', in this case University employers, may question the legitimacy of this assessment item and the potential for collusion between students, as the final advice letters can be near identical in both style and content. We maintain that this is not a problem as we actively encourage students to work together in preparing the advice for this client as they would for a live client. As with all experiential learning, the learning is in the doing - in this case legal research and drafting. The final letter (and possibly underpinning research findings) is merely the evidence of this process and it is assessed accordingly, subject to the usual rules to preserve academic integrity.

${ }^{22}$ For a more detailed discussion of the opportunities provided by effective simulation see: Caroline Strevens et al (op cit) and in particular chapters 1 (Paul Maharg and Emma Nicol, Simulation and technology in legal education, 17) - a meta analysis and chapter 4 (Susan Marsnik, Setting the stage: using simulation as a first day of class exercise, 87) - for an overview of what is needed for simulation to work well. 


\section{Oral examinations}

The third in our suggested package of assessment is the group oral examination (viva voce). At undergraduate level this is an innovative and unusual assessment in clinic but, if module feedback is anything to go by, popular with students in the clinic. As set out above, group work is an important element of experiential learning and most students in clinic would be expected to work as part of a group. Groups are responsible for the allocation of tasks and work together to create outputs, such as client advice letters. As so much of the learning in clinic takes place in groups we believe that this dynamic should be recognised in assessment. In our example the assessment is conducted as a group conversation, with individual marks being given to each of the participants.

When most people hear the expression 'viva' they think of an individual oral assessment such as the final element of a doctoral programme. It evokes images of an intimidating and unbalanced dialogue between the expert and the novice. As such, the use of individual oral assessments is not without its critics. To use the terminology from Van der Vleuten above, there are questions about its validity as there is the potential for variation in content and emphasis and possible misalignment of outcomes and assessment tasks. There are also studies setting out its low reliability in that the individual examiner's active participation in the examination can introduce bias. The effect of this is that each candidate may actually 
undertake a different assessment. ${ }^{23}$ Studies have also found evidence that the assessment tends to be more of a candidate's personality than their knowledge, and that the assessment is at a low taxonomic level in that it is a test of recall, rather than analysis. $^{24}$

We are very mindful of these criticisms, but believe that the use of a group, as compared with an individual, viva goes some way to mitigate against the shortcomings of the individual viva. For example, we address the validity concern by giving clear instructions about what will be assessed in the viva, and aligning the questions asked in the viva with the learning outcomes. The reliability concern can be countered by the presence of two or more assessors, at least four students (to provide the group dynamic) and video recording equipment in every assessment. Including a group oral examination within the assessment package of a credited clinic module is not without its problems. Colleagues (and students) have flagged up concerns such as the potentially negative influence of particularly dominant or reserved participants, resourcing issues such as the over-dependency on specific staff members, and the potentially intimidating effect of an unfamiliar assessment format. The biggest issue for the university level 'others' is measurability. For example, are assessors grading by comparison, or on the merits of an individual?

${ }^{23}$ For a useful discussion on oral assessment in higher education see Gordon Joughlin, Dimensions of Oral Assessment Assessment \& Evaluation in Higher Education, 23(4), 1998, 367-378.

${ }^{24}$ For a brief overview of the research on oral examination in medical education see Margery H. Davis \& Indika Karunathilake The place of the oral examination in today's assessment systems Medical Teacher 27(4), 2005, 294-297 
Our experience of conducting group vivas certainly proves that the positives outweigh the negatives, and we continue to be strong advocates of the academic benefit of creating a natural style conversation to assess students learning. As with the learning portfolio, we believe that a group viva could be used to capture and discuss a wide variety of clinical experiences. Within our package of assessments, we have decided to focus on the students' understanding of the nature and extent of the skills necessary to be an effective lawyer.

To give a flavour of how this might play out, we can return to the Group 1 firm set out above and explain what would happen in an oral assessment. For the purposes of this illustration the learning outcome on which assessment is based here is the extent of the students' appreciation of the range and nature of skills used by lawyers in carrying out their work for clients.

Following the formalities of explaining the format and setting up the recording equipment, one of the assessors asks an opening question such as "what are the principal considerations a legal adviser must take into account to ensure effective communication with whoever he or she has to deal with during the progress and management of a case?" In our experience this quickly turns into a conversation about the experiences the students have had, with relevant issues such as interview skills, legal and factual research and letter drafting discussed within the context of the client cases. The assessors ensure that all students are involved in the conversation by asking direct or follow-on questions. In most instances one or both 
of the assessors are familiar with the case under discussion and can make reference to specific learning events to facilitate greater reflective or analytical discussion.

Depending on the responses given the assessors can drill down into the depths of a student's knowledge and understanding including their familiarity with the relevant published literature.

During the assessment the assessors have a sequence of suggested questions that can be asked, but there is no prescribed format or order for these. The initial question is merely the trigger for discussion, and we try and keep naturally evolving conversations going. For example, it is not uncommon for students to start asking each other questions, or comparing their reflections on particular events with very little assessor involvement. One of the most refreshing aspects about this assessment is its authenticity - plagiarism or other academic misconduct is not possible, and there is less room for 'retro-fitted' (or even worse falsely fabricated) and hence unreliable evidence as is sometimes apparent in reflective writing..$^{25}$

The assessment can be timetabled for longer than is needed so the conversation usually ends when the assessors indicate that they now have sufficient evidence upon which to determine marks/grades. Students may be given a final opportunity to add anything else that they think the assessors should hear. Feedback can then be given either orally (although the conversation will probably have produced feedback 
during the discourse in exchanges between students and assessors) or provided after the event. The assessors need to maintain notes on each student's contributions during the viva and/or can rely on the recording that has been made.

On occasion, time permitting, the conclusion of the formalities has led to a further unassessed conversation about the clinical legal education more generally as most clinical programmes encourage dialogue and constructive critique.

Once the students have gone, the assessors then discuss the assessment and collectively allocate individual assessment marks then, or at some later stage.

The organisation and conduct of the viva is admittedly time-consuming. The flip side of this is that the assessment is over and done with (possibly including feedback) in one sitting. Evidence (based on student feedback - oral and in exit questionnaires) suggests that the assessment experience is viewed positively by all concerned.

This may be an example of the classic case of less being more in terms of the assessment input/output discussion.

\section{On-line assessment of professional standards}

Experiential learning has, at least until relatively recently, been predominantly face to face. There are many reasons for this and we are in no way advocating a radical overhaul of the community aspect that makes clinic so enjoyable, but it is inevitable and perhaps sensible with the advance of technology to harness the learning potential presented. 
There are a number of technology-based initiatives that could be mentioned here ranging from the use of recorded material which students can watch and comment on, to virtual, simulated and interactive case studies. ${ }^{26}$ It follows that if use can be made of the computer and internet to provide the source material for learning and teaching than this can also be turned into the means of assessing student (and other) performance and engagement with all aspects of their learning in clinic.

We want to provide what we think is a useful, if relatively unsophisticated, example of using e-technology for the assessment of one important aspect of clinical legal education. We have found that one of the key challenges in live-client work is ensuring that the required professional standards are met. Most, if not all, clinical programmes dealing with real clients will have some form of induction and training programme usually carried out in advance of the module or programme commencing. This explains to all concerned what is necessary to make the clinic run effectively and ensure compliance with professional standards. In our experience starting the first session by giving the students a hefty handbook and a set of rules can lead to many students being less than inspired, and can run the risk of the students starting the first interviews without knowing these important points as they have not had time to digest them.

\footnotetext{
${ }^{26}$ A useful introduction to the use of e-technology in law schools in general and clinic in particular, focusing on the SimPLE e-learning platform can be found in Wilson Chow and Firew Tiba, Professional legal education reviews: too many 'what's, too few 'how's, European Journal of Law and Technology 4 (1), 2013
} 
One way of encouraging the students to take this seriously and to focus on the content is to assess their understanding. This could, of course, be done in a number of ways. We suggest that a simple and effective method is to introduce a multiplechoice test that the students complete on-line. This can address the relevant general rules of professional conduct as well as the operation of the specific clinic. In our example there are 10 questions (some with sub-sections) that look at issues such as conflicts of interest, client confidentiality and the supervisory arrangements within our clinic. In our particular example students can take the assessment a number of times until they achieve the $100 \%$ success rate required. The clinical staff can see, online, who has done and completed the test and the students are told they cannot progress to seeing clients until they have passed. Other than the design of the exercise the resource input for the institution is minimal and the outcome at least shows that the students have had to consider key issues underpinned by the induction, training and feedback that they receive prior to and after the test is completed. Although this is most obviously a summative piece of assessment with no or limited feedback we believe it adds to the overall learning experience through increasing familiarity with operational and professional rules. The submission could be marked/graded but we feel that its real value is in focusing the students' mind on how they need to work in the clinic. We therefore make the jumping of this assessment hurdle a pre-requisite to module participation rather than a creditbearing component of the whole. 


\section{ASSESSING OURSELVES}

Having considered a range of different ways to assess 'them' one final point we would like to address is the assessment of ' $u s^{\prime}$. How do we evaluate our own contribution to experiential learning, and who are we evaluating this for? This topic is so rich that it could be the focus of another paper, but suffice to say here that an awareness of what we aim to achieve, what regulatory provisions we must satisfy and how we might improve what we do to enhance learning are crucial to curriculum design and review.

In the clinic, where real clients are concerned, one measure of assessment is our compliance with professional standards. The operation rules should provide the framework and these need to be monitored to make sure that any relevant changes to professional practice are taken into account and disseminated to everybody working in the environment.

Another area of assessment is the requirement to meet the quality assurance demands of our respective institutions - be that a university teaching or planning committee, a faculty board or the eagle eye of a sceptical dean. For example the 
decisions we make on the assessment of students on credited modules will be subject to this institutional scrutiny.

The student perspective is, of course, vital too and this may be garnered through exit questionnaires, other forms of module or programme feedback and, in the UK context, the National Student Survey. Whilst many may doubt the true value of the latter ${ }^{27}$, our institutions take the results seriously indeed, especially as it leads to the ubiquitous league tables, by university and subject area, and therefore a ranking through which public perception is influenced. ${ }^{28}$

Whatever one's views on the content, the principle of on-going evaluation from a range of stakeholder perspectives is important if the intention is to oversee and, as necessary, fine-tune provision to extract the maximum learning potential. For us this requires a process of near continuous assessment and reflection of what we are doing in clinic and what we hope to achieve.

\section{CONCLUSIONS}

\footnotetext{
${ }^{27}$ Might, for example the student take on the quality of teaching provision be used at some point to inform pay awards and/or promotion?

${ }^{28}$ For those especially interested the findings of the NSS can be seen at: www.hefce.ac.uk (accessed 2 November 2015)
} 
There is an old saying: 'pigs don't get fat by being weighed' ${ }^{29}$ As true as this adage might be pigs may stand a better chance of weight enhancement (if that is a good thing!) if we know what pigs weigh now as we can then decide what steps to take to provide any desired addition.

We have suggested in this paper that assessment is a key component to aiding learning, in part as a measuring point in the educational continuum and partly to provide feedback on how improvement can be made. Whilst many of the points we make are equally relevant to all forms of educational delivery, in the context of experiential learning certain forms of assessment lend themselves to the educational process. We have explored the creation of a package of assessment types to best serve the interests and requirements of 'us', 'them' and the 'others'. We do not consider this to be a definitive or perfect package, but we suggest that it goes some way to address some of the complications that are inherent in the assessment of learning in general and experiential learning in particular.

Some of us may wish that we could break away from the minutiae of summative assessment. Is a script really worth 54 or $57 \%$ ? More significantly, at least in a UK context, is it 69 or $70 \%$ ? Would a move towards a pass/fail system better facilitate learning so that less emphasis is placed on marks and grades and more on what is learnt and improving performance and understanding? In our obviously

\footnotetext{
${ }^{29}$ For an interesting discussion and slightly contrary view see: www.societyforqualityeducation.org/index.php/blog/weighing-a-pig-does-fatten-it) (accessed 1 November 2015)
} 
competitive world should the differentiation between the students who excel and those who do not do so convincingly, be done by personal references or other form of commendation instead?

We leave the discussion by re-stating the questions we set out at the start:

- Having set clear learning outcomes, do the means used for assessing whether they have been achieved relate specifically to each of the relevant outcomes?

- Are the outcomes and is the assessment regime fitting in terms of the level of the student's study, the juncture at which the outcome is expected to be achieved and when the assessment is to be carried out?

- Are the outcomes and means of assessment likely to be perceived by the tutor and student as applicable to the relevant study?

- Can the outcomes and assessment be logistically fitted into the period of study and any assessment slot that may follow it?

- Does the whole have credibility for tutor and learner? In other words is there 'buy-in' or ownership by all concerned?

We have suggested some answers to these questions for further consideration, and in the hope that less attention may eventually be spent on taking assessments and more on learning from them. 